\title{
PEÕES DO TRANSPORTE E DO TRECHO: mobilidade do trabalho em Barcarena ${ }^{1}$
}

\section{Marcel Hazeu}

Universidade Federal do Pará (UFPA)

\section{Nádia Socorro Fialho Nascimento}

Universidade Federal do Pará (UFPA)

\section{Mylena dos Santos Santana}

Universidade Federal do Pará (UFPA)

\section{Ana Caroline dos Santos Ferreira}

Universidade Federal do Pará (UFPA)

PEÕES DO TRANSPORTE E DO TRECHO: mobilidade do trabalho em Barcarena

Resumo: Este texto aborda a mobilidade do trabalho sob a lógica da superexploração do trabalho no contexto do (neo) desenvolvimentismo. Visa analisar a des-re-territorialização de trabalhadores provocada por processos pertinentes ao avanço capitalista na Amazônia. Tem por base um estudo sobre transformações sociais e mobilidade do trabalho e pesquisa empírica efetivada no município paraense de Barcarena, onde a implantação de fábricas e portos transformou a vida da comunidade local. Constata que grande contingente de trabalhadores foi inserido no mercado capitalista de trabalho e transformado em peões do transporte e do trecho para garantir a superexploração. Considera que as localidades envolvidas se tornaram territórios de exploração e passagem, sem a presença de qualquer processo local que poderia ser denominado de desenvolvimento regional.

Palavras-chave: Trabalho, migração, Amazônia, Barcarena.

PEONS OF TRANSPORT AND OF STRETCH: labor mobility in Barcarena

Abstract: This paper addresses labor mobility within the logic of super exploitation of the labor in the context of (neo) developmentalism. It aims to analyze the de-re-territorialization of workers by processes of the capitalist advance in the Amazon. Based on a study on social change and labor mobility, empirical research was carried out in the municipality of Barcarena of the state of Pará where the installation of factories and ports transformed the lives of the local community. Concludes that a large number of workers was inserted into the capitalist labor market and transformed into peons of transport and of stretch to ensure their super exploitation. The localities involved became territories of exploitation and transit without any local process that could be called regional development.

Key words: Labor, migration, Amazon, Barcarena. 


\section{INTRODUÇÃO}

Este artigo aborda a mobilidade de trabalho no contexto das migrações e transformações sociais vinculadas a mobilidades de peões no município de Barcarena/PA, onde se instalaram um complexo industrial de alumina/alumínio e caulim e portos para exportação destes produtos e do agronegócio (soja e gado).

Ele resulta das reflexões de um estudo maior, realizado nos anos de 2013 a 2015, quando da elaboração da tese O Não-lugar do outro: sistemas migratórios e transformações sociais em Barcarena (HAZEU, 2015) ${ }^{2}$, que coletou dados sobre as diversas mobilidades humanas e suas forças estruturantes. Identificaram-se quatro sistemas migratórios: 1. Deslocamentos forçados; 2. Movimentos pendulares e periferização habitacional metropolitana; 3. Transportadores da exportação; e 4.Mobilidade de trabalho.

Os impactos econômicos, políticos e socioculturais do avanço dos grandes empreendimentos na Amazônia no contexto (neo) desenvolvimentista ${ }^{3}$ podem ser analisados na sua complexidade através do estudo das migrações, conforme sugere o sociólogo australiano Stephen Castles (2010), estudioso de migrações no contexto de globalização. Isto permite abordar e analisar as transformações que ocorrem na sociedade, nas comunidades e na vida das pessoas diretamente atingidas.

A região amazônica foi gradativamente envolvida no avanço da economia capitalista globalizada e das políticas desenvolvimentistas dos governos brasileiros, ditatoriais autoritários, democráticos neoliberais ou sociodemocratos. Sua inserção na economia capitalista visa, historicamente, a exploração das riquezas naturais e seu potencial hidrelétrico, além da inerente especulação fundiária e apropriação de recursos públicos.

Barcarena é um município amazônico distante $40 \mathrm{~km}$ de Belém, que até os anos 1970 se caracterizava como uma sociedade ribeirinha, rural, que vivia da roça, caça, pesca e extrativismo. A vida da população se voltava para os rios que serviam como vias de transporte, fonte de alimentos, de água potável, lugar de banho, lavagem de roupa e de lazer, além do comércio dos produtos da roça, pesca e extrativismo. Muitas pessoas trabalhavam também sob condições precárias em engenhos, olarias, fazendas, grandes plantações e casas de família (MOURA, 1990; SOUZA, 2006).

Os anos 1980 trouxeram a maior transformação social pela qual o município tinha passado até então. As olarias, serrarias, fábricas de palmito, plantações de abacaxi, coco e laranja, os sítios e roças perderam espaço para quatro grandes empreendimentos voltados para à produção e exportação de alumínio: o porto de Vila do Conde, a fábrica da Alunorte, a estação de energia da Eletronorte e nova área urbana, chamada Vila dos Cabanos. No contexto de um governo autoritário e da expansão do capital internacional em busca de territórios para investir e de recursos naturais, em especial os recursos energéticos hídricos e minerais, Barcarena foi inserida num megaprograma de investimento do Governo Federal Brasileiro - o Programa Grande Carajás (PGC) $)^{4}$-, criado para organizar e articular investimentos que já estavam sendo feitos no Pará. Dentro desta perspectiva, o município foi escolhido naquele momento como polo industrial-portuário na cadeia produtiva do alumínio, e posteriormente, na década de 1990, ganhou um segundo braço de investimentos industriaisportuários para a exploração e exportação de caulim. Entre outras alterações, o município cresceu na importância como área portuária de exportação de outros produtos, diversificando a atuação dos portos existentes e criando novos, com destaque para a exportação de gado vivo ${ }^{5}$ e de soja.

Barcarena não é um território de extração de riquezas ou de geração de energia, mas um corredor de exportação, um lugar de infraestrutura, de logística, de portos, de concentração de indústrias de transformação primária. O município sofre com a poluição das indústrias, desapropriações, o movimento de cargas e a transformação da sua organização espacial, que condenam as suas outras vocações à falência, como o turismo, a pesca, o extrativismo ou a produção agrícola, devido aos impactos ambientais, econômicos, fundiários e sociais do complexo portuário-industrial.

A implantação das indústrias e portos tem influenciado as dinâmicas da população de Barcarena em diversos aspectos, como a desapropriação das suas terras, deslocamentos forçados e poluição. Ocorreu uma inserção parcial de parte da sua população original no mercado de trabalho dominado pelas empresas e empreiteiras. Estruturou-se, ao mesmo tempo, a mobilização de pessoas de outras localidades para trabalhar no município ou passar trabalhando pelo mesmo.

A formação de trabalhadores livres e em movimento mudou a vida das famílias e a lógica da produção e reprodução local, num processo de desterritorialização organizado e planejado, vinculado a uma reterritorialização precária, o que o geografo Rogério Haesbaert (2010) chama de desre-territorialização. Desde então pessoas circulam entre inúmeras obras, indústrias, minas e portos no Brasil, sem fazer parte da comunidade local, inseridas como um exército da ocupação capitalista.

Segundo Fialho Nascimento e Hazeu (2015, p. 288, grifo dos autores), a riqueza gerada em Barcarena

[...] em função do complexo portuárioindustrial produz, concomitantemente, pobreza de uma grande parte da 
população tradicional e migrante, aprofundando as expressões da 'questão social' na região.

\section{TRABALHADORES EM MOVIMENTO}

Duas categorias específicas detrabalhadores postas em movimento são alvos da superexploração que caracteriza a produção capitalista globalizada: os trabalhadores de transporte (os peões do transporte) e os trabalhadores da construção e manutenção das obras e fábricas (os peões do trecho).

O economista Jean Paul de Gaudemar (1977) observou que na dinâmica de crises e acelerações econômicas a passagem dos operários de uma empresa para outra, de um canto do país para outro, se torna uma necessidade, além do que:

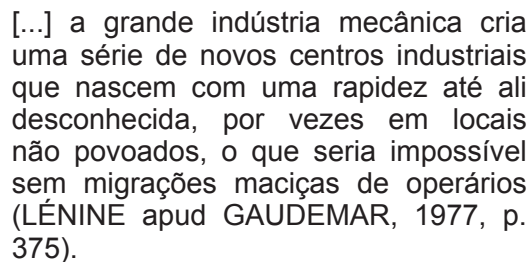

Esta mobilidade do trabalho é um reflexo e parte da constituição da oferta de mão de obra na divisão capitalista do trabalho. Segundo Gaudemar (1977), a mobilidade do trabalho não é uma livre circulação de trabalhadores numa dinâmica de busca de equilíbrio, mas é regida pelas lógicas do mercado e desenvolvimento capitalista, com suas contradições e sinalizações em relação à economia capitalista:

Não seria exercer grande violência sobre o pensamento explícito de Marx fazê-lo afirmar que doravante a emancipação dos trabalhadores passa pela reivindicação coletiva do direito a imobilidade ou ainda do direito à automobilidade. (GAUDEMAR, 1977, p. 400-401).

Trata-se de uma mobilidade do trabalho para garantir a lucratividade das empresas e que chega ser uma mobilidade condicionada, em termos de destinos e de liberdade de ir e vir, pelos recrutamentos e pagamentos do transporte do lugar de origem ao lugar do trabalho, com endividamento desde então, contrariando uma lógica de trabalhadores supostamente livres num mercado. A não contratação do trabalho local se relaciona à mesma possibilidade intrínseca de superexploração ${ }^{6}$ do trabalhador deslocado e distante de suas redes sociais de proteção e reprodução. Discutindo as ideias de Ruy Mauro Marini, Santana e Balanço (2012, p. 5) definem a superexploração como:
[...] apropriação do tempo de trabalho excedente através 0 prolongamento da jornada de trabalho, aumento da intensidade do trabalho e a conversão do fundo de consumo necessário do operário em fundo de acumulação do capital.

A condição de isolamento do trabalhador da comunidade onde se inseriu no mercado do trabalho não pode se perpetuar, pois com o passar do tempo criam-se novas redes sociais e se articula a vinda de pessoas da rede originária. A temporariedade do contrato é, portanto, parte integrante da estratégia da mobilidade do trabalho controlada e organizada.

Haesbaert (2010, p. 255) se refere à mobilidade desses trabalhadores temporários como os

[...] globalizados de baixo, aqueles que, enquanto trabalhadores em empregos temporários e sem estabilidade, vivem viajando ou mudando de cidade em busca de trabalho.

Esses trabalhadores "[...] acabam sendo obrigados a uma mobilidade permanente em busca de emprego." (HAESBAERT, 2010, p. 255).

2.1 Peões do transporte: sempre em movimento

O sistema de transporte em Barcarena de produtos expressa seu lugar na economia mundial em termos de participação nas cadeias produtivas, como mostra a listagem dos principais produtos que passaram pelos portos de Barcarena em 2013 e 2014: Alumina, Alumínio, Bauxita, Boi Vivo, Calcário, Carvão mineral, Caulim, Contêineres ${ }^{7}$, Coque, Ferro-gusa, Fertilizantes, Manganês, Óleo combustível, Piche, Soda cáustica, Soja (VALENTE, 2013; COMPANHIA DAS DOCAS DO PARÁ, 2014a, 2014b).

Há uma estreita relação entre a exploração de recursos naturais no Pará e a demanda nos mercados internacionais, com base na organização do transporte de mercadorias e da inserção de trabalhadores da área de transporte e sua passagem por Barcarena.

As pessoas envolvidas no transporte de produtos marcam uma dinâmica nos territórios por onde passam e onde param. Os que vivem do e no transporte são trabalhadores móveis nas rotas das mercadorias e fazem de Barcarena um dos seus territórios. Vistos como forasteiros ou passantes, eles formam uma categoria com presença permanente e estrutural, apesar de mudar constantemente de composição. Eles formam a base do sistema migratório que acompanha os fluxos de mercadorias e interagem com os territórios cruzados e conectados por esses fluxos. 
Muitos dos navios, por exemplo, que atracam no porto em Barcarenanavegam com bandeiras de países que não são dos proprietários dos navios, mas que cobram menos impostos e não exigem direitos trabalhistas, possibilitando uma superexploração de marinheiros nesses navios. Estes são chamados países de bandeiras baratas ou flagsofconvenience - FOC (INTERNATIONAL TRANSPORT WORKERS'S FEDERATION, 2012). Dados sistematizados dos navios que atracam em Barcarena, a partir do site Marine Traffic ([20-?]), indicam que $68 \%$ destes navios navegam com bandeira de um país citado na lista de FOC Countries.

Dos 5.150 tripulantes de navios internacionais que desembarcaram em Barcarena em 2013, com uma média de 13 tripulantes por navio, eram das seguintes nacionalidades: Filipinas (1.539); Síria (1.533); Índia (329); Ucrânia (284); República Tcheca (259); Croácia (195); China (171); Polônia (146); Paquistão (113); Rússia (112) e outros (469) (Dados enviados depois de solicitados ao Ministério da Justiça pelo site (BRASIL, 2014). Como mostram estes dados, as tripulações geralmente são oriundas de países sem frota naval expressiva e nem dos países que emprestaram suas bandeiras. Os marinheiros das Filipinas, principal origem dos marinheiros, são conhecidos como "[...] baratos e fáceis, que não reclamam e aceitam condições degradantes de trabalho." (ROOIJAKKERS, 2002).

Os caminhões, o outro elo de transporte na organização dos fluxos de produtos que passam por Barcarena, interligam lugares sem acesso fluvial com os centros industriais e portuários ou fazem a distribuição fina de mercadorias para fins específicos.

Segundo dados solicitados a Companhia das Docas do Pará (CPD), no período de 2 de janeiro a 30 de junho de 2013, 24.874 caminhões com cargas entraram e 10.310 caminhões carregados saíram do porto da Vila do Conde, evidenciando que se trata de um porto de exportação, onde circulam cerca de 195 caminhões por dia. A listagem das placas dos caminhões possibilitou a identificação do local de origem de cada veículo (Registro disponível no site do Sistema Nacional de Segurança Pública (SINESP)). Além dos caminhões que circulam entre as fábricas e o porto, a maioria emplacada no Pará (50\%), circula um número significativo de caminhões procedentes de Minas Gerais (20\%) e de São Paulo (25\%).

A movimentação de navios e caminhões no município não criou um mercado de trabalho para a população local. Segundo o Censo de 2010, em Barcarena há somente 175 pessoas registradas como marinheiros de coberta e afins, além de 40 pessoas como capitães, oficiais de coberta e práticos, a maioria atuando em embarcações locais. A participação de caminhoneiros de Barcarena é de 43 trabalhadores no ambiente urbano e 98 no ambiente rural (INSTITUTO BRASILEIRO DE GEOGRAFIA E ESTATÍSTICA, 2011).

2.2 Peões do trecho: circulando atrás de obras e manutenção

Desde os anos 1970, a abertura de estradas, a construção de hidrelétricas, a implantação dos polos de mineração e incentivos à criação de gado e à indústria madeireira transformaram a região amazônica, usando o discurso do espaço vazio que precisava ser explorado e ocupado. A população já existente nunca foi considerada, nem como atores sociais com direito à terra e poder de decisão, nem como potencial para a próprio processo de ocupação capitalista.

A invasão pela política desenvolvimentista criou a necessidade de formar uma força de trabalho abundante e móvel para ser inserida nos momentos e lugares estratégicos para o avanço do programa. Investimentos em infraestrutura (estradas, pequenas cidades), juntamente com o estímulo à migração (colonização) e ao recrutamento organizado, precisavam criar as condições em termos de mão de obra para as obras gigantescas que faziam parte do PGC.

A construção da barragem de Tucuruí foi um dos primeiros grandes projetos na Amazônia, que iniciou a produção e reprodução de mão de obra móvel para a expansão do projeto capitalista na Amazônia, financiado com recursos públicos, em benefício do capital transnacional (brasileiro e internacional) na região.

A alta rotatividade dos trabalhadores nunca criou empregos estruturais ou fixos. Na construção da Barragem de Tucuruí, nos anos 1970, por exemplo, chegou-se a uma rotatividade inacreditável de renovar todo o efetivo de quase 20 mil trabalhadores do canteiro em dois meses (ALVEZ; THOMAZ JUNIOR, 2012). A inserção destes trabalhadores num município causa aumento de demandas por serviços públicos que geralmente não são atendidos, deixando tanto os novos trabalhadores quanto a população nativa em precárias condições.

Para a implantação do complexo industrialportuário-urbanístico em Barcarena, nos anos 1980, mais de 12 mil trabalhadores se somaram à população local de 20 mil habitantes. Muitos trabalhadores migrantes vieram das obras de construção de hidrelétrica de Tucuruí, da instalação do complexo no Jari, de municípios vizinhos e de outros estados, recrutados por empreiteiras ou atraídos pelas notícias difundidas pelo país sobre as oportunidades de trabalho na região.

Os empregos gerados eram temporários e a quantidade flutuava a cada ano, dependendo da fase das obras e da abertura ou fechamento de frentes de trabalho, dinâmica que caracteriza as grandes obras na Amazônia, lembrando que: 
[...] em outubro de 1984, esses trabalhadores nos canteiros de obras eram 12.000 , número que caiu para 7.000 em 1985, devido à conclusão da primeira fase da ALBRAS. (FONTES, 2003, p. 68)

Em 1989, a própria Albras tinha 2.354 empregados em Barcarena, sendo $65,6 \%$ oriundos do Pará e $34,4 \%$ de outros estados. Os trabalhadores do Pará eram recrutados e qualificados em Belém, o que sugere que a grande maioria era belenense (TOURINHO, 1991). Já neste período a Albras utilizava a contratação de mão de obra através de empresas terceirizadas - 410 postos de trabalho em 1989 -para serviços de transporte, manutenção, limpeza e alimentação (TOURINHO, 1991).

A Albras e as demais empresas instaladas posteriormente implantaram modelos de gestão desenvolvidos no âmbito das empreses multinacionais e nos cursos de administração, com a metodologia de Controle de Qualidade Total, adequando as empresas às novas lógicas do mercado mundial (MONTEIRO; MONTEIRO, 2007; CASTRO, 1995). Uma das consequências deste modelo foi a redução dos postos de trabalho diretos e a terceirização de grande parte dos serviços.

Segundo Monteiro e Monteiro (2007), em 1990, a Albras empregou 2.356 empregados, com uma produtividade anual por trabalhador de 82 toneladas de alumínio, e em 2006 eram 1.357 empregados, com uma produtividade anual por trabalhador de 336 toneladas de alumínio. A terceirização também foi observada a partir das reclamações trabalhistas e ações na justiça contra a Albras. Enquanto que em 1990 e 1991 os processos ainda eram de empregados vinculados à Albras, em 1997, a maioria era de funcionários das empresas prestadoras de serviços à Albras.

Dados sobre a origem dos empregados em 2013 na empresa Hydro (antiga Albrás e Alunorte) mostra a importância da mobilidade do trabalho na organização das empresas. A maioria dos trabalhadores (1.295 pessoas ou $82 \%$ ) é paraense, mas menos de $10 \%$ nasceu em Barcarena. São de municípios próximos (Belém, Abaetetuba, Cametá, Igarapé Miri), outros (12\%) são oriundos de outros estados, principalmente do Maranhão, Minas Gerais, Amapá, Rio de Janeiro e São Paulo ${ }^{8}$.

Esta mobilidade de trabalhadores não se encerrou com o fim das primeiras obras, mas se repetiu numa escala menor a cada nova obra instalada, desde as fábricas de Caulim até os portos construídos recentemente pela Bunge ou em construção pela Hidrovias do Brasil.

\subsection{Peões de trecho do próprio lugar}

Além dadinâmicadeentradadetrabalhadores de outras partes do Brasil, os processos de desapropriações das terras e moradias da população local, e a instalação das empresas de transformação mineral e portuárias em Barcarena, anunciavam e provocavam a transformação das formas e relações de trabalho locais. A população ribeirinha, extrativista e pescadora, que manteve relações de trabalho não assalariadas ou parcialmente vinculadas ao mercado capitalista, foi forçada a conviver como novo modelo de organização do trabalho, como também com os migrantes que vieram em busca de emprego.

Parte dos moradores de Barcarena se inseriu nos fluxos de trabalhadores que são contratados por empreiteiras para trabalhar em obras e indústrias, inicialmente em Barcarena, depois, principalmente, fora de Barcarena, seguindo a estratégia da dispersão e desterritorialização dos trabalhadores, reforçando as formas de exploração do trabalho.

$\mathrm{Na}$ maioria das famílias em Barcarena há alguém que se inseriu neste mercado, como montadores de andaimes, eletricistas, operadores de máquinas, caldeiras, soldadores, pedreiros, técnicos de administração (HAZEU, 2015). Trabalhar nas empresas se tornou uma perspectiva de ascensão social, de participar do desenvolvimento, do projeto de modernidade e uma estratégia de subsistência familiar.

Estes membros de famílias tradicionais têm se inserido no trabalho nas empresas, inicialmente em Barcarena, e quando as portas se fecharam no município, através de empreiteiras com atuação nacional para trabalhar em obras fora de Barcarena. Os principais Estados de destino dos membros das famílias entrevistadas (HAZEU, 2015) que se inseriram no mercado de trabalho como peões de trecho e também segundo os dados do Serviço Nacional de Emprego (SINE) ${ }^{9}$ são Pará, Rio de Janeiro, Pernambuco, Amapá, Minas Gerais, Maranhão, São Paulo, Mato Grosso, Ceará e Rondônia, Bahia, Amazonas, Espírito Santo, Goiás, Paraná e Rio Grande do Sul.

Quando comparados os dados acima com o quadro do estado da origem dos funcionários da Hydro, observa-se que os principais estados de origem de trabalhadores desta empresa são os mesmos para onde os trabalhadores de Barcarena se deslocam. Assim, as grandes obras e indústrias têm criado uma mão de obra voltada para suas demandas, e em seguida provocam a sua circulação entre as demais obras e indústrias no Brasil.

Os peões de trecho nas famílias tradicionais são, em geral, jovens da segunda geração depois do início da implementação do complexo portuárioindustrial-urbanístico, que já incorporaram a perspectiva de trabalhar nas empresas como projeto de vida, seduzidos pela proposta da modernidade e inserção no processo da globalização econômica, cultural e social, forçados pelas novas tecnologias e pela impossibilidade de viver conforme os modos de vida tradicionais que foram impactados com 
a implantação do complexo industrial portuário e urbanístico.

Porém, nesta nova condição e caminho, eles também encontram as contradições do mercado do trabalho capitalista, a superexploração e o desemprego, conforme o depoimento de alguns peões de trecho $^{10}$ de Barcarena.

Eu trabalhei lá como eletricista, mas ganhando como ajudante e como ajudante na carteira. Hoje meu irmão tá tomando conta de uma equipe. Ele ainda não é encarregado não classificaram ainda ele né, mas a obra tudo fica por conta dele lá. (Informação verbal) ${ }^{11}$.

No máximo que dá é um ano, o máximo que dá de obra é um ano de elétrica porque são muitas empresas e cada empresa pega uma etapa, aí como são muitas empresas, aí encurta aí. (Informação verbal) $)^{12}$.

Cada noventa dias a gente ganha uma semana pra passar em casa. Eu não dei mais conta, passou quatro anos eu não dei mais conta né, porque a gente fica muito enclausurada né. (Informação verbal) ${ }^{13}$

A gente de fora não, a gente trabalha direto se eu passo noventa dias lá, é noventa dias trabalhado, não descanso de segunda a sexta de sete às dez da noite, normalmente, e sábado e domingo direto é incansável. É nisso que a gente ganha dinheiro, depois do horário fazendo hora extra. (Informação

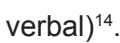

Atualmente, foi reforçada a tendência das empresas de não contratar mão de obra local, mesmo qualificada ou classificada, em decorrência de uma lógica de dinâmica de trabalho exigida dos trabalhadores, menos aceita por quem tem casa e família próximas do trabalho. Trata-se de exigências apresentadas como vantagens para o peão de trecho: "[...] possibilidades de horas extras, turmas extras.", e "[...] alojamento no local do trabalho, diminuindo o tempo de viagem entre o trabalho e local de moradia.", como formas de incrementar o salário, que somente é ligeiramente mais alto do que no mercado local em Barcarena. (Informações verbais $)^{15}$.

As qualificações da maioria dos trabalhadores de Barcarena são voltadas para a implantação de obras e pouco para a fase operacional do empreendimento, o que dificulta sua contratação. Outro fator mencionado em relação à dificuldade de entrada no mercado de trabalho local é de que muitos empreiteiros que prestam serviços às indústrias e portos são de outros estados e trazem suas próprias equipes de trabalho.

Em outros setores do mercado do trabalho no Brasil esta prática também se repete e envolve inclusive recrutamento de trabalhadores em Barcarena para o trabalho rotineiro e exaustivo nos frigoríficos, uma das indústrias que mais contrata trabalhadores no Brasil. A distância de Barcarena até as fábricas parece ser uma vantagem para o regime de trabalho, que em muito parece com a realidade das grandes obras de construção.

A empresa Sadia, por exemplo, recorre ao SINE como apoio ao seu processo de recrutamento e legitimação do regime de trabalho. Entre 2011 e 2013, só o SINE (2014) Pará encaminhou 2.884 pessoas para trabalhar na Sadia. A pesquisa de Fernando Heck (2013), Degradação anunciada do trabalho formal na Sadia, em Toledo (PR), mostra como a empresa se estruturou a partir da superexploração dos seus trabalhadores.

Nas palestras de recrutamento ${ }^{16}$ da Sadia no SINE de Barcarena é apresentada, de forma explícita, a regime de exploração: os interessados ganharão pouco, morarão em condições mínimas e controladas (oito pessoas por casa, sem geladeira, sofá, beliches; permitido para levar apenas uma mala de tamanho médio e duas caixas de papelão, proibido receber visitas sem autorização etc.) e terão descontos no salário (lanche, refeição, aluguel, seguro de vida, água, energia, danos provocados ao alojamento etc.).

\section{CONCLUSÃO}

No contexto das obras em todo o Brasil, o estado do Pará é o segundo estado mais importante em termos de origem dos trabalhadores no trecho, só perdendo para o estado do Maranhão (SANTOS, 2011). A contratação de forma temporária e a alta rotatividade imprimem uma aceleração da desterritorialização desses trabalhadores e são a base para a sua superexploração, com apoio direto do poder público. As políticas públicas de recrutamento e de emprego (como o SINE), de Segurança Pública (como a presença da Força Nacional na repressão às manifestações dos trabalhadores), de financiamento público das grandes obras na Amazônia e as legislações que permitem a flexibilização das relações de trabalho se constituem como apoio governamental a esta forma de organização do trabalho.

O sistema migratório de mobilidade do trabalho criou uma dinâmica nacional de circulação de trabalhadores contratados por períodos curtos, de seis meses até dois anos, sob as condições de superexploração do trabalho. Barcarena é tanto destino quanto origem desses fluxos de trabalhadores, sendo o mercado local de trabalho cada vez mais fechado para a população local. Os peões de trecho de Barcarena se inserem na circulação pelos pais atrás das obras e empregos, mas os ganhos desta inserção não oferecem condições para os trabalhadores e suas famílias 
saírem da situação de pobreza e marginalização, enquanto as empresas lucram com as formas de mobilidade e exploração desses trabalhadores, que no trecho não encontram um lar, e em casa temem novos deslocamentos forçados.

O peão de trecho vive no trecho, onde há trabalho temporário, de alta intensidade $\mathrm{e}$ exploração, na perspectiva de ganhos melhores. Ele vive em alojamento, passa quase 24 horas e sete dias por semana no canteiro de obras, no terreno da empresa, é completamente estranho ao contexto no qual se insere o empreendimento, que, por si só, geralmente é uma invasão num território com territorialidades anteriores. Ele se torna para a empresa e para o lugar onde se insere um ser sem direito de permanecer, cuja história é desconsiderada e que vira um uniforme de uma empresa. As empresas e empreiteiras procuram minimizar as referências que formam a identidade do trabalhador, além de sua funcionalidade para as empresas. Destituem-no de sua terra e local de moradia, de convivência familiar e comunitária e de sua relação de tempo e espaço.

Porém, a superexploração encontra também fortes resistências por parte dos trabalhadores, mesmo estando em condições desiguais de poder. Os deslocamentos forçados são contestados pelos trabalhadores por ações judiciais, retomadas de territórios e permanências relutantes. No âmbito do trabalho nas obras, os peões de obra, adquirindo conhecimento e experiência no próprio trecho, organizam greves e rebeliões nos canteiros de obra, largam o trabalho antes do tempo determinado nos contratos temporários e exigem outras condições de contratação. O trabalhador de trecho acumula conhecimento e consciência de classe na sua circulação pelo país e convivência com sempre novos colegas, precisando desenvolver estratégias contra hegemônicas, enfrentando o poder do capital e do Estado que financia e favorece o modelo da superexploração.

A inserção totalizante de Barcarena na globalização econômica é baseada na exploração territorial, que se traduz na inserção precária da sua população em termos de oportunidades de trabalho e emprego; da degradação de suas condições de vida e segurança de moradia; da passagem constante de caminhões e navios, caminhoneiros e marinheiros, que buscam e criam em Barcarena serviços de atenção às suas demandas diversas; da presença de trabalhadores temporários ou pendulares de outros municípios, para quem Barcarena é somente um lugar de trabalho, de ganhar dinheiro e de diversão descompromissada; e da saída de trabalhadores de Barcarena para os vários cantos do Brasil, que deixam suas famílias e vivem uma realidade familiar separada, com convivência esporádica, insegurança e saudades.
A organização da economia e mercado em termos de mobilidade do trabalho afirma um processo clássico de rotatividade de trabalhadores, que se deslocam de uma obra ou indústria a outra, conforme a dinâmica de recrutamento, subcontratação e piques de demanda por trabalho. Esta dinâmica põe as pessoas em permanente movimento, através de empreiteiras e serviços terceirizados, e as inserem em atividades sob regime de superexploração (longas jornadas de trabalho, baixos salários, condições de reprodução precárias), inclusive os caminhoneiros e marinheiros. Nesta organização do trabalho não há somente alienação do trabalho, mas também do lugar, pois ninguém é do lugar e nem da empresa, sendo (super)explorado e posto em permanente circulação.

\section{REFERÊNCIAS}

ALVES, J.; THOMAZ JUNIOR, A. A migração do trabalho para o complexo hidrelétrico madeira. Jornal do Trabalho. In: JORNADA DO TRABALHO, 12. Presidente Prudente, 2012. Anais... 17 p. Disponível em: <http://www.proceedings.scielo.br/ pdf/jtrab/n1/32.pdf>. Acesso em: 25 mar. 2014.

\section{BRASIL. Ministério da justiça. Mensagem eletrônica n 136/2014 - SIC/DIREX/DP. Brasília, DF, 2014.}

CASTELO, R. O novo desenvolvimentismo e a decadência ideológica do pensamento econômico brasileiro. Serviço Social e Sociedade, São Paulo, n. 112, p. 613-636, out./dez. 2012.

CASTLES, S. Entendendo a migração global: uma perspectiva desde a transformação social. Revista Internacional de mobilidade humana, Brasília, DF, ano 18, n. 35, p. 11- 43, 2010.

CASTRO, E. Racionalidade e novos padrões na gestão do trabalho em grandes empresas na Amazônia. Paper do NAEA, Belém, v. 54, p. 1-8, 1995.

COMPANHIA DAS DOCAS DO PARÁ. Movimentação de mercadoria: relatório gerencial contendo a movimentação de mercadorias, descrita por tipo de carga e por natureza de movimentação estatísticas de 2013. Belém, 2014a. Disponível em: <https://www.cdp.com.br/345>. Acesso em: 10 set. 2014

Origem e destino das mercadorias: relatório gerencial contendo a movimentação de mercadorias, descrita por Porto de origem e destino da mesma - estatísticas de 2013. Belém, 2014b. Disponível em: <https://www.cdp.com.br/345>. Acesso em: 10 set. 2014. 
FIALHO NASCIMENTO, N.; HAZEU, M. Grandes empreendimentos e contradições sociais na Amazônia: a degradação davida no município de Barcarena, Pará. Argumentum, Vitória, v. 7, n. 2, p. 288-301, jul./dez. 2015.

FONTES, E. O peão de trecho e o peão de casa: Identidades operárias entre os trabalhadores da construção civil de Barcarena no canteiro de obras da ALBRAS/ALUNORTE. Novos Cadernos NAEA, Belém, v. 6, n. 1, p. 65-82, 2003.

GAUDEMAR, J. Mobilidade do trabalho e acumulação do capital. Lisboa: Estampa, 1977.

HAESBAERT, R. O mito da desterritorialização: do "fim dos territórios" à Multiterritorialidade. Rio de Janeiro: Bertrand Brasil, 2010.

HAZEU, M. O Não-lugar do outro: sistemas migratórios e transformações sociais em Barcarena. 2015. 337 f. Tese (Doutorado em desenvolvimento sustentável) - Núcleo de Altos Estudos Amazônicos, Universidade Federal do Pará, NAEA, Belém, 2015.

HECK, F. M. Degradação anunciada do trabalho formal na Sadia, em Toledo (PR). 2013. $217 \mathrm{f}$. Dissertação (Mestrado em geografia) - Faculdade de Ciências e Tecnologia, Universidade Estadual Paulista, Presidente Prudente, 2013.

INSTITUTO BRASILEIRO DE GEOGRAFIA E ESTATÍSTICA. Censo Demográfico 2010. Rio de Janeiro, 2011. Disponível em:<http://www.ibge.gov. br/home/estatistica/populacao/censo2010/>. Acesso em: 31 dez. 2014.

INTERNATIONAL TRANSPORT WORKERS'S FEDERATION. FOC Countries. London, 2012. Disponível em: <http://www.itfglobal.org/flagsconvenience/flags-convenien-183.cfm>. Acesso em: 9 set. 2014.

MARINE TRAFFIC. Chamadas de Porto: partidas e chegadas. [S. I.], [20--?]. Disponível em:<http:// www.marinetraffic.com/pt/ais/index/port_moves/all>. Acesso em: 20 fev. 2015.

MONTEIRO, M.; MONTEIRO, E. Amazônia: os (des) caminhos da cadeia produtiva do alumínio. Novo Cadernos NAEA, Belém, v. 10, n. 2, p. 87-102, dez. 2007.

MOURA, E. A. F. Laranjal sem laranjas: condições de vida após a implantação dos grandes projetos na Amazônia. In: ENCONTRO NACIONAL DE ESTUDOS POPULACIONAIS, 7., 1990, Belo Horizonte. Anais... Belo Horizonte: ABEP/NEPO, 1990. p. 197-224.
ROOIJAKKERS, P. Filipijnsezeevaart in de problemen: meerzeeliedendanbanen. Tambuli, 2002. Não paginado. Disponível em: <http://tambuli. $\mathrm{nl} /$ tambak/article.php? articleid=292>. Acesso em: 11 mar. 2015.

SAMPAIO JR, P. de A.. Desenvolvimentismo e neodesenvolvimentismo: tragédia e farsa. Serviço Social e Sociedade, São Paulo, n. 112, p. 672-688, out./dez. 2012.

SANTANA, P. M.; BALANÇO, P. Superexploração do trabalho, dependência e (sub) desenvolvimento capitalista: elementos para um debate quase esquecido. In: ENCONTRO NACIONAL DE ECONOMIA, 40., 2012, Porto de Galinhas. Anais.... Porto de Galinhas: ANPEC, 2012.

SANTOS, E. C. Os homens por trás das grandes obras do Brasil. São Paulo: Childhood, 2011.

SOUZA, W. C. A. Vinte e cinco anos depois: efeitos sociais do Projeto ALBRÁS/ALUNORTE em São Lourenço (Barcarena-Pará). 2006. 101 f. Dissertação (Mestrado em Ciências Sociais) - Centro de Filosofia e Ciências Humanas, Universidade Federal do Pará, Belém, 2006.

TOURINHO, H. L. Z. (Coord.). Repercussões sócioeconômicas do complexo industrial ALBRAS/ ALUNORTE em sua área de influencia imediata. Belém: IDESP, 1991.

VAlente, A. M. (Coord.). Plano mestre Porto de Vila do Conde. Florianópolis: LabTrans, 2013.

\section{NOTAS}

1 Texto escrito para a mesa redonda $O$ desenvolvimento regional no contexto do (neo)desenvolvimentismo: trabalho, migrações e grandes empreendimentos na VII JOINPP em 2015

2 Tese de doutorado em desenvolvimento sustentável do Núcleo da Altos Estudos Amazônicos (NAEA), UFPa

3 O uso do termo (neo)desenvolvemtismo se faz aqui com aspas para indicar a problematização do termo com base em Sampaio Jr. (2012) e Castelo (2012)

4 PGC foi extinto formalmente em 1991, mas perpetuando através dos projetos e planos criados para a região nas décadas seguintes

5 No dia 06 de outubro de 2015, Barcarena foi palco de desastre ambiental de repercução nacional e internacional no qual um navio carregado de 5 mil bois afundou no porto do município.

6 Com base nas ideias de Ruy Mauro Marini, Santana e Balanço (2012, p. 5) definem a superexploração como "Apropriação do tempo de trabalho excedente através o prolongamento da jornada de trabalho, 
aumento da intensidade do trabalho e a conversão do fundo de consumo necessário do operário em fundo de acumulação do capita."

7 Madeira, caulim, silício, carne bovina, pimenta.

8 Dados produzidos e disponibilizados pela empresa a pedido do autor.

9 Dados disponibilizados pelo SINE depois da solicitação sobre os Estados de destino de trabalhadores de Barcarena encaminhados pelo SINE Pará (2011-2013).

10 Nomes fictícios

11 Depoimento retirado da entrevista de Carlos.

12 Depoimento retirado da entrevista de Rivaldo

13 Depoimento retirado da entrevista de Bruno

14 Depoimento retirado da entrevista de Alex

15 Depoimento retirado das entrevistas.

16 Em 2013 foi acompanhada uma palestra de recrutamento e entrevistada uma ex-funcionária da Sadia que tinha voltado para Barcarena.

\section{Marcel Hazeu}

Graduado em Ciências Ambientais

Doutor em Desenvolvimento Sustentável pela Universidade Federal do Pará (UFPA)

Professor visitante Programa de Pós-Graduação em Serviço Social (PPGSS) do Instituto de Ciências Sociais Aplicadas (ICSA) da UFPA

E-mail: celzeu@gmail.com

\section{Nádia Socorro Fialho Nascimento}

Assistente Social

Doutora em Serviço Social pela Universidade Federal do Rio de Janeiro (UFRJ)

Professora da Faculdade de Serviço Social (FASS) e do PPGSS/ICSA da UFPA

E-mail: nadiasfialho@gmail.com

\section{Mylena dos Santos Santana}

Graduanda em Serviço Social pela UFPA

Bolsista do Laboratório de Pesquisas e Práticas Sociais na Amazônia (LABPSAM) da UFPA

E-mail: mylenasantana88@gmail.com

\section{Ana Caroline dos Santos Ferreira}

Graduanda em Serviço Social pela UFPA

Bolsista do LABPSAM da UFPA

E-mail: 1904carolineferreira@gmail.com

Universidade Federal do Pará - UFPA

Instituto de Ciências Sociais Aplicadas - Avenida Augusto

Corrêa, 01 - Guamá

CEP: $66075-110$ 